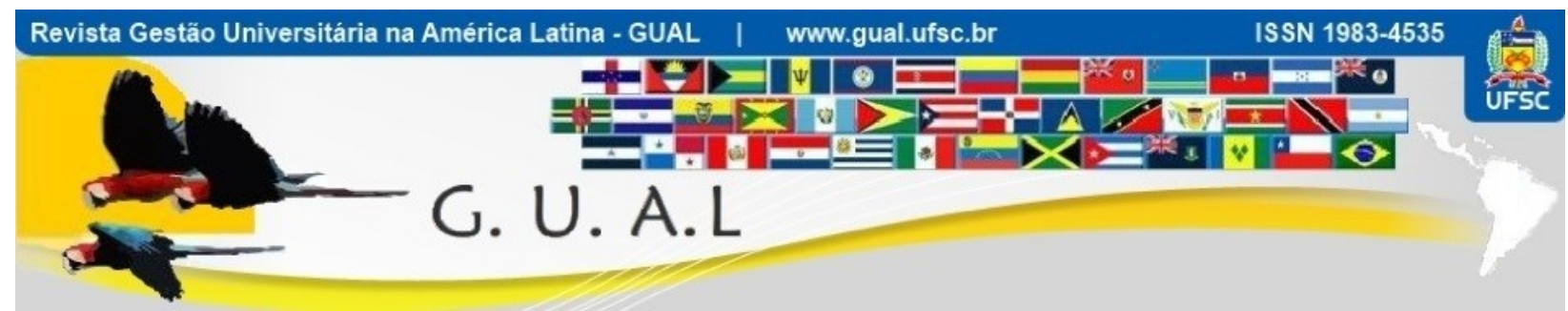

DOI: http://dx.doi.org/10.5007/1983-4535.2018v11n1p71

\title{
GESTÃO ESTRATÉGICA EM INSTITUIÇÕES PRIVADAS DE ENSINO SUPERIOR
}

\author{
STRATEGIC ADMINISTRATION IN PRIVATE HIGHER EDUCATION \\ INSTITUTIONS
}

Francisca Juliana de Andrade Araújo, Mestranda

Universidade Federal do Ceará - UFC

juliana18andrade@hotmail.com

Augusto Cézar de Aquino Cabral, Doutor

Universidade Federal do Ceará - UFC

cabral@ufc.br

Sandra Maria dos Santos, Doutora

Universidade Federal do Ceará - UFC

smsantos@gmail.com

Maria Naiula Monteiro Pessoa, Doutora

Universidade Federal do Ceará - UFC naiula@ufc.br

Recebido em 07/junho/2016

Aprovado em 04/outubro/2017

Sistema de Avaliação: Double Blind Review

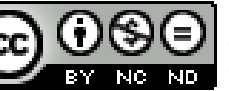

Esta obra está sob uma Licença Creative Commons Atribuição-Uso. 


\title{
RESUMO
}

O ensino superior no Brasil apresentou um crescimento acelerado a partir do final da década de 1990, quando a Lei de Diretrizes e Bases da Educação (LDB) de 1999 possibilitou que a iniciativa privada entrasse nesse mercado. Atualmente, as Instituições de Ensino Superior (IES) privadas representam mais de $88 \%$ das IES brasileiras. O crescimento acelerado do número de IES levou a uma maior preocupação com a formalização da gestão estratégica nessas instituições. Nesse contexto o objetivo desse estudo é identificar como ocorre o processo de gestão estratégica nas IES privadas cearenses. Realizou-se uma pesquisa de natureza qualitativa que teve a entrevista como instrumento de coleta. Os sujeitos foram os gestores de cinco faculdades privadas localizadas no município de Fortaleza (CE). Os resultados obtidos demonstram que uma das principais motivações para a adoção do processo foi o aumento da competitividade, além de destacar a tecnologia como aliada em praticamente todas as fases e a cultura de resistência à mudança como uma das barreiras para o sucesso do processo. Ainda foi possível verificar que o processo envolve toda a organização, desde a alta administração, com o planejamento até o nível operacional com a implementação.

Palavras-chave: Ies. Estratégia. Gestão Estratégica.

\begin{abstract}
The higher education in Brazil presented an accelerated growth starting from the end of the decade of 1990, when the Law about Diretrizes e Bases da Educação (LDB) (Law of Guidelines and Bases of the Education) of 1999 made possible that the deprived initiative entered in that sector. The accelerated growth of the number of Higher Education Institutions (HEI) took for a larger concern with the formalization of the strategic administration in those IES. In that context the objective of that study is to identify how it happens the process of strategic administration inside the IES from Ceará. At present, the private Institutions of Higher education called (IES) act more than $88 \%$ of Brazilian colleges. Was held un a research of qualitative nature that used the interview as collection instrument. The subjects were the managers of five located universities in the municipal district of Fortaleza (CE). The obtained results demonstrate that one of the main motivations for the adoption of the process was the increase of the competitiveness, besides detaching the technology as allied in practically all of the phases and the resistance culture to the change as one of the barriers for the success of the process. It was still possible to verify that the process involves all the organization, from the high administration, with the planning until the operational level with the implementation.
\end{abstract}

Keywords: Hei. Strategy. Strategic Administration. 


\section{INTRODUÇÃO}

O ensino superior no Brasil tem crescido consideravelmente nos últimos anos. O surgimento de novas instituições, principalmente privadas, que já representam cerca de $88 \%$ do total de IES no país, segundo dados do e-MEC (2015), tem facilitado o acesso ao ensino superior e promovido maior competição nesse setor. Diante desse cenário, Machado (2008) ressalta que a utilização de uma gestão estratégica torna-se um diferencial competitivo.

O principal guia para o planejamento estratégico nas IES é o Plano de Desenvolvimento Institucional (PDI) que hoje é uma ferramenta obrigatória para que a instituição seja avaliada pelo Ministério da Educação (MEC) e, apesar de contribuir para o planejamento estratégico, de acordo com Silva et al. (2014), não se confunde com este, visto que enquanto o PDI é definido por decreto e tem diretrizes e tempo determinado, o planejamento é uma das etapas de um processo maior, denominado gestão estratégica.

A gestão estratégica, conforme Mintzberg et al. (2006), segue um processo composto pelas fases de planejamento, formulação, implementação/implantação e controle que podem ocorrer de forma holística ou linear. De acordo com a forma de desenvolvimento das estratégias, elas são classificadas em deliberadas ou emergentes. As primeiras são referentes àquelas estratégias que foram previamente pensadas por meio do desenvolvimento de um plano formal podendo ou não se realizar e as segundas dizem respeito às estratégias que se desenvolveram a partir das necessidades percebidas, mas que formaram uma sequência de ações que foram aceitas como padrão pela a organização. Porém, mais importante do que classificar o processo de estratégia como deliberado ou emergente é entender como ele ocorre (MINTZBERG et al., 2006).

Nesse contexto, este trabalho tem o seguinte problema de pesquisa: Como ocorre o planejamento estratégico nas IES privadas cearenses? O objetivo geral do artigo é identificar como ocorre o processo de gestão estratégica nas IES privadas cearenses e como objetivos específicos, têm-se: (1) identificar os principais atores em cada fase; (2) identificar as principais motivações; (3) identificar as principais barreiras na implementação das fases; (4) identificar os fatores facilitadores de cada fase.

A utilização do planejamento estratégico como uma ferramenta de diferencial competitivo tem se mostrado eficiente, uma vez que, o desenvolvimento organizacional está relacionado com a capacidade dos gestores diante da formulação, implantação e acompanhamento das estratégias (MINTZBERG et al., 2006) e, de acordo com Matos, 
Venâncio e Dutra (2014), apesar do crescente interesse sobre a gestão estratégica nas IES, esse é um assunto ainda pouco explorado.

O presente estudo é de natureza qualitativa descritiva, tendo sido utilizados além de levantamento bibliográfico, uma pesquisa de campo. A coleta de dados se deu por meio de dados secundários, colhidos através de sites da internet como e-MEC, por exemplo, e dados primários mediante entrevista. Os sujeitos da pesquisa foram os gestores das IES privadas cujos conceitos institucionais tenham níveis iguais ou superiores a 3 (três), conforme os critérios do Instituto Nacional de Educação e Pesquisas Educacionais Anízio Teixeira.

Esse artigo está estruturado em cinco seções. A seção dois apresenta uma revisão da literatura sobre os conceitos de estratégia e o processo de planejamento. Em seguida, na seção três são descritos os aspectos metodológicos da pesquisa, tais como a natureza da pesquisa, bem como o processo de coleta de dados. A seção quatro apresenta os resultados obtidos. Considerações finais são apresentadas na seção cinco.

\section{GESTÃO ESTRATÉGICA}

A seguinte seção tem como objetivo descrever de forma ampla a gestão estratégica, para tanto, além das diversas visões de gestão estratégica apresentadas, tem-se como subseções a definição de estratégia, destacando-se a visão de vários autores; o processo de gestão estratégica e; por fim, a gestão estratégica nas IES que é, o foco desse trabalho.

A gestão estratégica é um processo amplo e complexo que tem como fim o desenvolvimento futuro da organização e a integração entre as suas fases. (NICOLAU, 2001). Corroborando, Coelho Jr (2003, p. 83) afirma que "o pilar da gestão estratégica se encontra, não no trabalho realizado em departamentos isolados, mas sim por processos, tornando as atividades organizacionais integradas, sistêmicas e interdependentes.

Oliveira Jr. e Castro (2006) ressaltam que a gestão estratégica consiste na concentração dos esforços dos gestores para formular as estratégias que guiarão o caminho da organização, por meio não somente de um processo formal de elaboração da estratégia, mas também da identificação dos conhecimentos internos, aprendizagem organizacional e o aproveitamento das competências a fim de ganhar vantagem competitiva, portanto, para se entender a gestão estratégia, faz-se necessário o conhecimento das diversas definições de estratégia. 


\subsection{ESTRATÉGIA}

Diversos autores já trataram sobre o tema estratégia cuja dificuldade da definição colabora para que não haja um conceito universalmente aceito (NICOLAU, 2001; MINTZBERG et al.,2006; HERNANDES; LOMBARDI, 2011). De acordo com Mintzberg et al. (2006) as estratégias podem ser definidas a partir de cinco conceitos, que são conhecidas como os "5 Ps" da estratégia, são eles, estratégia como plano, pretexto, padrão, posição e perspectiva. As estratégias, como plano, são vistas como intenções elaboradas formalmente e declaradas anteriormente a ação com o objetivo de orientá-las para o alcance de resultados posteriores; como pretexto, estratégias são manobras para superar um oponente ou concorrente; padrão é referente aquela estratégia que é fruto de uma sequência de ações não formalizadas que foram se desencadeando e a organização reconhece como válidas; a estratégia como posição é utilizada para localizar a organização no ambiente externo; e a estratégia como perspectiva é a análise interna da organização a fim de encontrar suas características intrínsecas.

Os autores supracitados definem ainda a estratégia corporativa como um modelo de decisões de uma empresa que determina e revela os objetivos a serem alcançados, criando as políticas e planos para atingir esses objetivos e definindo o escopo de negócios que a empresa vai adotar, tendo como principais características o fato de serem criadas propositalmente, conscientemente e antes das ações às quais vão se aplicar.

Quanto ao desenvolvimento da estratégia, Mintzberg et al. (2006) ressaltam que a estratégia pode se desenvolver de forma planejada e realizada; planejada, mas não realizada; e não planejada, mas realizada (estratégias emergentes). Nesse sentido, as estratégias emergentes são consideradas como padrão que surgem a partir da necessidade de ações que são reconhecidas pela organização criando um plano formal através de uma sequência de atividades. Desenvolvem-se sem intenções claras ou apesar destas e promovem o aprendizado organizacional, uma vez que são realizadas sem formulação preestabelecida (HERNANDES; LOMBARDI, 2011).

As estratégias deliberadas, por sua vez, são todas as que são previamente planejadas pela organização e podem se concretizar (realizadas) ou não (MINTZBERG et al., 2006; HERNANDES; LOMBARDI, 2011). Uma estratégia, no entanto, não ocorre de forma totalmente deliberada ou emergente, já que as barreiras imprevisíveis que a organização enfrenta dificultam a realização total do planejamento, assim como, a necessidade de um 
norteador para orientação em relação aos objetivos pretendidos "obriga" a organização definir, pelo menos, algumas estratégias (MINTZBERG et al., 2006).

Nesse sentido, Mintzberg et al. (2006) identificam algumas estratégias mais deliberadas e outras mais emergentes, mostradas no quadro 1, em que nos extremos estão as estratégias puramente deliberadas e puramente emergentes (de cima para baixo) e entre elas, têm-se estratégias que são mais deliberadas e outras mais emergentes. A partir dessa perspectiva, é possível observar que quanto mais deliberada as estratégias forem, mais dificultarão o aprendizado organizacional, visto que, os obstáculos encontrados para realização destas foram poucos e quanto mais emergentes mais dificuldade se encontrará para controlá-las, por não ter parâmetros para se comparar (MINTZBERG et al., 2006; HERNANDES; LOMBARDI, 2011). 
Quadro 1 Tipos de estratégia

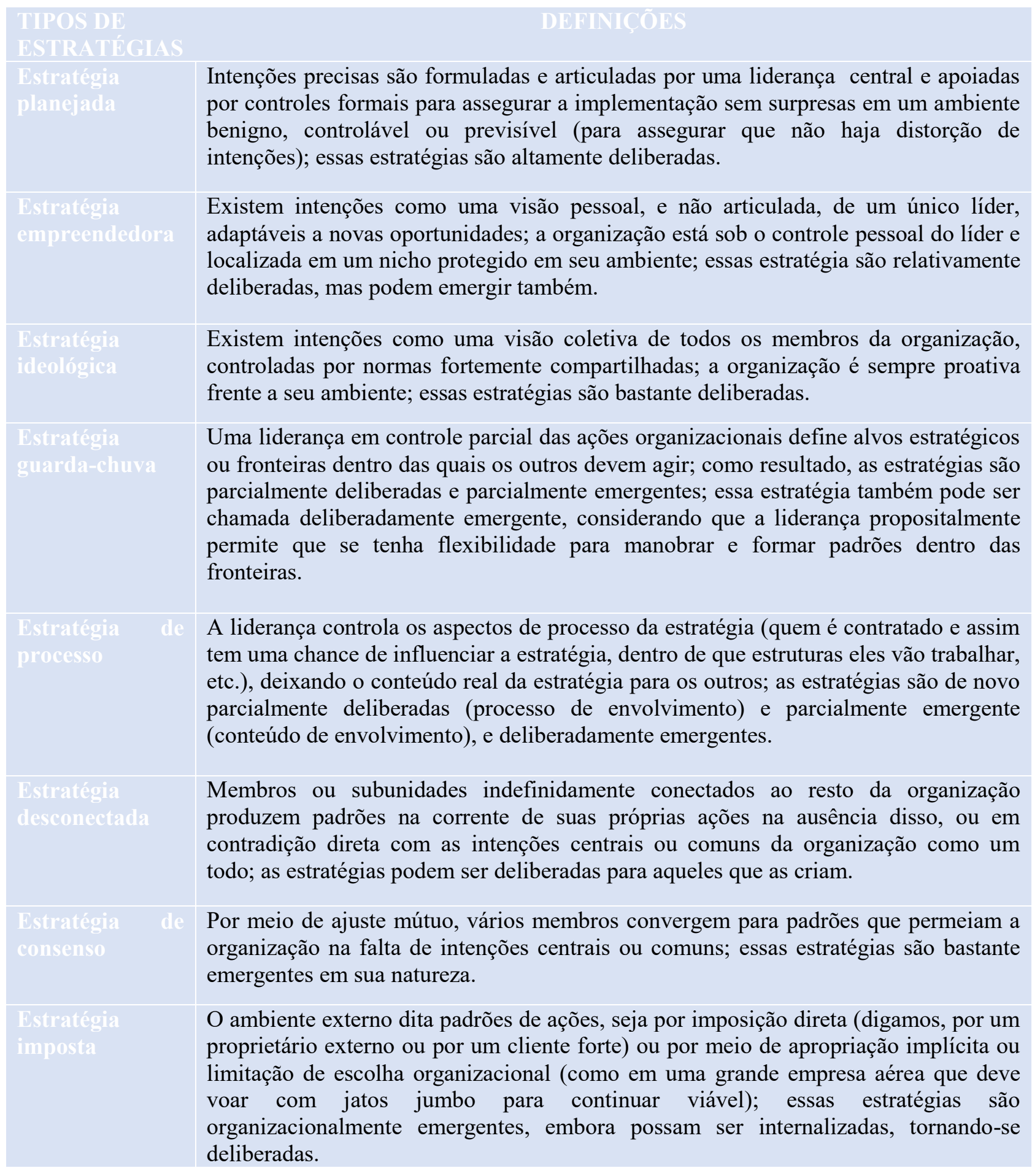

Fonte: Adaptado de Mintzberg et al. (2006)

A gestão estratégica, segundo Weber e Klein (2013, p. 4) “é (..) muitas vezes confundida com a estratégia em si ou com o planejamento estratégico formal", porém, trata-se de um processo mais complexo e abrangente que, envolve a elaboração da estratégia para o desenvolvimento organizacional em que o planejamento estratégico tem o papel de 
direcionador. Para Mintzberg et al. (2006), a gestão estratégia é um processo cíclico que engloba, além do planejamento, as fases de formulação, implementação e controle, conforme detalhado a seguir.

\subsection{PROCESSO DE GESTÃO ESTRATÉGICA}

De acordo com Mintzberg et al. (2006), o processo estratégico é composto por quatro fases: planejamento, formulação, implantementação e controle. Essas fases podem ser desenvolvidas uma após a outra (linearmente) ou de forma interligada contemplando uma visão global da organização (holística).

\subsubsection{PLANEJAMENTO}

Planejamento estratégico consiste na elaboração de um plano formal em que a alta administração define: (1) estratégias organizacionais, que conforme Andrade e Frazão (2011), trata-se da seleção dos cursos de ação a serem seguidos; (2) missão, definida como razão de ser da organização; (3) visão de negócio, que consiste em como a empresa pretende ser ou se vê no futuro; (4) valores, que são os princípios que serão zelados pela organização; (5) objetivos que, diz respeito aonde se quer chegar; e (6) metas que são objetivos determinados pelo fator temporal.

De acordo como Araújo e Silva e Gonçalves (2011), a importância do planejamento estratégico se deve a necessidade de uma programação prévia por parte das organizações a fim de minimizar as consequências das mudanças que ocorrem no ambiente, destacando-se como uma importante ferramenta que visa orientar os gestores na tomada de decisão auxiliando no desempenho organizacional por meio da concentração de esforços que visa o alcance dos objetivos.

Os elementos que compõem o planejamento estratégico permitem uma definição do escopo da organização e o desenvolvimento de uma visão geral da empresa. Para Andrade e Frazão (2011), o planejamento estratégico é um processo contínuo que acontece de forma holística, ou seja, a partir da visão da organização como um todo e é fortemente influenciado por fatores intrínsecos e extrínsecos. Nesse enfoque, o planejamento representa uma metodologia que favorece a correta utilização dos recursos da organização perante as mutações de seu ambiente a fim de se beneficiar com as oportunidades e lidar melhor com as ameaças. 


\subsubsection{FORMULAÇÃO}

Formulação da estratégia é a obtenção de informações referentes ao ambiente interno e externo da organização e a decisão do que fazer diante da análise das informações a fim de alcançar os objetivos planejados. A fase de formulação da estratégia tem como principais subatividades a análise do ambiente interno e externo da organização, por meio da identificação das forças e fraquezas no primeiro e oportunidades e ameaças no segundo; avaliando também os recursos disponíveis e estimando de forma objetiva a capacidade da organização de aproveitar as forças e oportunidades e/ou de lidar com as fraquezas e ameaças. Uma importante ferramenta nessa fase é a análise SWOT (Strengths, Weaknesses, Opportunities, Threats) que, favorece a análise interna e externa da organização (MINTZBERG et al., 2010; HERNANDES; LOMBARDI, 2011).

Dessa forma, essa fase do processo auxilia no alcance dos objetivos organizacionais através do desenvolvimento de metas baseadas nas informações obtidas e uma visão global da organização, além de direcionar a organização no melhor caminho para que os objetivos planejados e as metas formuladas sejam implementadas com sucesso (MINTZBERG et al., 2006; BEPPLER; PEREIRA; COSTA, 2011).

\subsubsection{IMPLANTAÇÃO/IMPLEMENTAÇÃO}

Para Mintzberg et al. (2010) a etapa de implementação não deve ser separada da formulação da estratégia, isto porque implantar diz respeito a colocar em prática tudo o que foi previamente definido a partir das análises de ambiente interno e externo e determinação dos recursos materiais, técnicos, financeiros e gerenciais da empresa, por isso, se essas etapas forem pensadas como processos independentes, a estratégia formulada correrá um grande risco de ser mal implementada e, consequentemente, a eficácia dos objetivos será afetada.

Nessa etapa do processo, as estratégias, formuladas pela alta administração (nível estratégico), são comunicadas ao nível hierarquicamente inferior, ou seja, aos gerentes operacionais das divisões para serem transformadas em planos de ação e implementadas de fato (SILVA, 2003). A atenção para essa fase no processo estratégico tem sido crescente porque, quando negligenciada, a implementação pode sofrer com alguns obstáculos que impedem a eficácia de todo o processo.

De acordo com Barbosa e Drummond (2008) a má formulação da estratégia, o desalinhamento entre estratégia e estrutura, mecanismos de incentivos inadequados e ausência 
do envolvimento dos trabalhadores no processo de formulação e implementação são alguns dos principais impecilhos para a implantação eficaz da estratégia. Silva (2003) complementa ressaltando que a comunicação entre as fases do processo é determinante para o sucesso ou fracasso dos objetivos, por isso é fundamental que todos os níveis envolvidos na implementação estejam cientes tanto da estratégia como dos processos que contribuem para a sua implementação.

\subsubsection{CONTROLE}

Nessa fase é realizada uma comparação de tudo que foi planejado com o que foi realizado corrigindo-se os desvios encontrados a fim de ajustar os planos e auxiliar na manutenção dos objetivos, metas, estratégias e projetos estabelecidos (ARAÚJO; SILVA; GONÇALVES, 2011; HERNANDES; LOMBARDI, 2011). Complementando esta definição, Oliveira et al. (2015) consideram que esta fase é uma das mais importantes dada a possibilidade de avaliar a evolução dos planos estabelecidos no planejamento e impedir que as falhas que causaram desvios se repitam no processo. Dessa forma, pode-se considerar que o controle e o planejamento são interdependentes porque, de acordo com Mintzberg et al. (2006), não tem como existir controle sem planejamento e este deixa de influenciar sem a existência daquele.

Mintzberg et al. (2006 p. 291) ressaltam ainda que "o controle estratégico significa manter as organizações em sua trajetória estratégica: assegurar a realização das estratégias pretendidas, sua implementação como esperado, com recursos apropriadamente alocados". De acordo com Andrade e Frazão (2011 p.25) "o processo de controle envolve avaliação de desempenho, comparação do desempenho real com o desejado, análise dos desvios e tomada de ação corretiva".

A formalização do processo de gestão estratégica tem recebido maior atenção pelas Instituições de Ensino Superior do Brasil, conforme Machado (2008), devido ao aumento do número de IES nos últimos anos, como será apresentado, a seguir.

\subsection{GESTÃO ESTRATÉGICA EM IES}

De acordo com os dados do INEP - Instituto Nacional de Educação e Pesquisas Educacionais Anízio Teixeira, a partir do final da década de 1990, houve um aumento no número de instituições de ensino superior no Brasil, com destaque para as instituições privadas. Este aumento pode ser relacionado com a criação da lei n. 9394/96 - Lei de 
Diretrizes e Bases da Educação Nacional (LDB) - que promoveu a ampliação do acesso ao ensino superior e com as políticas públicas de financiamento estudantil, que facilitaram o ingresso de novos estudantes e, consequentemente, geraram maior concorrência nesse mercado que até então era visto como pouco promissor (MAINARDES; MIRANDA; CORREIA, 2011; SARFATI; SHWARTZBAUM, 2013).

O mercado das IES no Brasil continua a crescer, atualmente, há no país cerca de 2.644 IES, das quais 2.332 (88\% do total) são instituições privadas (e-MEC, 2015). Diante desse cenário, Machado (2008) ressalta que a necessidade de uma gestão organizada tem se tornado cada vez mais evidenciada nessas organizações:

\begin{abstract}
Muitos outros setores já passaram pelo choque da concorrência e sobreviveram, agora chegou a vez das instituições de ensino. Ou elas aderem a um modelo de negócios mais contemporâneo e responsivo ou assistir-se-á nos próximos anos ao que nunca foi visto antes: IES privadas sendo vendidas, fundidas e tendo suas portas fechadas. Entre outros desafios que as IES privadas enfrentam nos nossos dias, destaca-se o da necessidade de ter um planejamento/ estratégico estruturado e de uma melhor gestão da competitividade (MACHADO, 2008, p.16)
\end{abstract}

A preocupação com a formalização e estruturação da gestão estratégica tem sido crescente nas Instituições de Ensino Superior. O Plano de Desenvolvimento Institucional (PDI) é o principal guia e consiste em um documento que se desenvolveu a partir da Lei Federal n ${ }^{\circ} 10.861$ com a instituição do Sistema Nacional de Avalição da Educação Superior SINAES (BRASIL, 2004). O SINAES tem como principal objetivo melhorar a qualidade da educação superior brasileira e utiliza vários instrumentos para mensurar a qualidade do ensino, entre eles, a avaliação institucional ou Conceito Institucional (CI) que é composto por duas modalidades de avaliação: a autoavaliação (ou avaliação interna) e avaliação externa realizada por comissões designadas pelo INEP que fazem visitas in loco. Os resultados são expressos por meio de indicadores de qualidade numa escala de cinco níveis, em que os níveis iguais ou superiores a 3 (três) indicam qualidade satisfatória (INEP, 2015).

Outro instrumento de avaliação relevante é o plano de desenvolvimento institucional que em 2006 tornou-se obrigatório para que as instituições de ensino superior sejam avaliadas em qualquer etapa de sua existência. Essa avalição é realizada por meio de orientação das ações organizacionais, de acordo com o conjunto de normas vigentes e destacando as habilidades institucionais a fim de promover uma resposta rápida aos ensejos desse segmento (ALMINO et al., 2012; SILVA et al., 2014). 
De acordo com Silva et al. (2014 $\neg)$, apesar de o PDI contribuir para planejamento estratégico, este não se confunde com aquele, porque enquanto o primeiro tem um caráter pragmático e definição temporal a partir de decreto, o segundo faz parte de um processo maior denominado gestão estratégica e utiliza de métodos participativos para delimitar as previsões que ultrapassam os eixos propostos para a elaboração do PDI.

\section{METODOLOGIA}

O presente estudo tem natureza qualitativa que, de acordo com Gray (2012), tem como principal foco entender as formas como as pessoas agem e explicar suas ações. Quanto aos objetivos, trata-se de uma pesquisa descritiva cujo propósito é obter informações sobre determinada população (ROESCH, 2006). O método utilizado pode ser classificado, de acordo com May (2004), como Survey, que visa descrever ou explicar características ou opiniões de uma determinada população.

A coleta de dados foi dividida em duas partes, primeiro foi realizada a coleta de dados secundários que consistiu na busca no site do e-MEC por IES privadas, localizadas na cidade de Fortaleza, com conceito institucional igual ou maior que três. Nessa primeira busca, foram identificadas 18 IES privadas, das quais 15 são classificadas como faculdades, 2 como centro universitários e 1 universidade. Optou-se então por trabalhar com foco nas faculdades, já que representam $83 \%$ da lista de IES privadas de Fortaleza.

No segundo momento, verificou-se que 2 (duas) faculdades listadas estavam desativadas, dessa forma, a lista foi reduzida a 12 (doze) IES. Os gestores das 12 faculdades foram contactados por meio de telefonemas e/ou e-mails e 5 retornaram o contato e agendaram o dia para a coleta dos dados primários que, foram coletados por meio de entrevistas semiestruturadas com questões abertas permitindo, segundo Collis e Hussey (2005), a inclusão de perguntas mais complexas e perguntas de seguimento, além de explicações mais precisas por parte do entrevistado.

As entrevistas foram direcionadas aos diretores ou coordenadores de cada instituição baseadas em um roteiro que abrangia todas as fases da gestão estratégica. A entrevista continha vinte e cinco perguntas divididas em quatro categorias: planejamento, formulação, implementação e controle, de acordo com o referencial teórico, e foram realizadas no período entre 11 e 27 de maio de 2015 com duração média de trinta minutos, cada uma.

Com o consentimento dos respondentes, as entrevistas foram gravadas para posterior transcrição e análise de conteúdo que, segundo Silvia e Fossá (2015), consiste em uma técnica 
que deve ser realizada de forma sistematizada, composta por quatro fases: (1) na pré-análise, foi realizada a leitura de todo o conteúdo da entrevista a fim de sistematizar as ideias iniciais; (2) a exploração do material ocorreu com a definição de unidades de codificação em que o texto é recortado e dá origem as quatro categorias, a saber, planejamento, formulação, implementação e controle; (3) o tratamento dos resultados se deu com a análise comparativa do material a fim de enquadrá-lo nas devidas categorias e identificar convergências e divergências; (4) e a interpretação que consistiu na articulação teoria-empiria.

\section{ANÁLISE DOS RESULTADOS}

Nessa seção, são descritas, de forma geral, as respostas dadas pelos gestores entrevistados. Além de perguntas referentes ao perfil dos respondentes (quadro 2), as 22 questões sobre o assunto foram alocadas em quatro categorias de acordo com os objetivos específicos do trabalho. Dentro de cada categoria, que são referentes às fases do processo de gestão estratégica, buscou-se identificar quais são os principais atores, as barreiras encontradas e os fatores que favorecem cada fase, além da motivação para prática do processo.

\subsection{PERFIL DOS RESPONDENTES}

Como é possível observar a partir do quadro 2, a gestão de maior parte das instituições analisadas está sob a responsabilidade de profissionais com formação acadêmica em administração de empresas e titulação de mestre ou doutor, além de experiência na área de, no mínimo, 10 (dez) anos. Esses dados podem ser reflexo da necessidade de uma gestão formalizada que, conforme Machado (2008), tem se tornado cada vez mais evidente nesse setor devido ao aumento da concorrência que se intensificou no final da década de 90 .

Quadro 2 Perfil dos respondentes

\begin{tabular}{|c|c|c|c|c|c|}
\hline Instituições & $\mathbf{A}$ & B & $\mathrm{C}$ & D & $\mathbf{E}$ \\
\hline Cargo & $\begin{array}{l}\text { Diretor } \\
\text { geral }\end{array}$ & $\begin{array}{l}\text { Diretor } \\
\text { acadêmico }\end{array}$ & Diretor geral & $\begin{array}{l}\text { Diretor } \\
\text { acadêmico }\end{array}$ & Coordenador geral \\
\hline $\begin{array}{l}\text { Formação } \\
\text { acadêmica }\end{array}$ & $\begin{array}{l}\text { Engenhe } \\
\text { iro civil }\end{array}$ & $\begin{array}{l}\text { Mestre em } \\
\text { adm. em } \\
\text { doutor em } \\
\text { engenharia } \\
\text { de produção } \\
\end{array}$ & $\begin{array}{l}\text { Mestre em } \\
\text { administração } \\
\text { de empresas }\end{array}$ & $\begin{array}{l}\text { Doutor em } \\
\text { administração } \\
\text { de empresas }\end{array}$ & $\begin{array}{lr}\text { Mestre } & \text { em } \\
\text { administração } & \text { de } \\
\text { empresas } & \end{array}$ \\
\hline $\begin{array}{l}\text { Tempo no } \\
\text { setor }\end{array}$ & 15 anos & 39 anos & 10 anos & 20 anos & 15 anos \\
\hline
\end{tabular}

Fonte: Elaborado pelos autores (2015) 


\subsection{PRINCIPAIS ATORES DO PROCESSO DE GESTÃO ESTRATÉGICA}

As respostas dos diretores das cinco instituições, em relação aos atores responsáveis por cada fase do processo de gestão estratégica foram condensadas e apresentadas no quadro 3.

Quadro 3 Principais atores do processo de Gestão estratégica

\begin{tabular}{|c|c|c|c|}
\hline Planejamento & Formulação & $\begin{array}{l}\text { Implantação/ } \\
\text { implementaçã }\end{array}$ & Controle \\
\hline $\begin{array}{l}\text { A fase } r \begin{array}{r}\text { de } \\
\text { planejamento, em }\end{array} \\
\text { todas as instituições, } \\
\text { é } \\
\text { responsabilidade da } \\
\text { alta administração, } \\
\text { formada pelos } \\
\text { diretores de cada } \\
\text { unidade de negócios } \\
\text { com a apoio da } \\
\text { coordenação, na } \\
\text { instituição "A" e } \\
\text { "C". O diretor geral } \\
\text { e ras } \\
\text { coordenadores ou } \\
\text { diretores discutem } \\
\text { as metas e elaboram } \\
\text { o planejamento no } \\
\text { nível estratégico, }\end{array}$ & $\begin{array}{l}\text { Os diretores e } \\
\text { coordenadores são } \\
\text { os principais } \\
\text { responsáveis por } \\
\text { esta fase e utilizam, } \\
\text { para tanto, dados } \\
\text { referentes ao } \\
\text { mercado e a própria } \\
\text { instituição. }\end{array}$ & $\begin{array}{l}\text { Em todas as } \\
\text { instituições, os } \\
\text { responsáveis pela } \\
\text { implementação das } \\
\text { estratégias são os } \\
\text { coordenadores e suas } \\
\text { respectivas equipes. }\end{array}$ & $\begin{array}{l}\text { O monitoramento é } \\
\text { realizado pelos } \\
\text { coordenadores de equipe, } \\
\text { na maioria das instituições } \\
\text { consideradas. } \\
\text { instituição D, entretanto, } \\
\text { essa fase está sob a } \\
\text { responsabilidade dos } \\
\text { diretores, com o auxílio do } \\
\text { setor de controladoria que, } \\
\text { transforma os dados em } \\
\text { gráficos comparando as } \\
\text { estratégias planejadas e } \\
\text { implementadas. }\end{array}$ \\
\hline
\end{tabular}

Fonte: Dados da pesquisa (2015)

A partir do exposto no quadro 3, é possível observar que o que é definido na fase de planejamento nas IES e os responsáveis por essa etapa corrobora com a visão de Mintzberg et al. (2006) que definem planejamento estratégico como a elaboração de um plano formal, em que a alta administração elabora as estratégias, missão, visão, valores, objetivos e metas.

Outro ponto que requer atenção é a comunicação entre atores do processo. Nas IES consideradas, os planos de ação são repassados aos envolvidos (coordenadores, professores e departamentos), assim como os prazos para a realização, por meio de reuniões específicas para este fim que acontece, em média, a cada 45 dias. Na instituição A, entretanto, o fluxo de informações acontece em tempo real, de acordo com o gestor A que diz que "através de uma 
ferramenta que informa aos agentes em tempo real, as estratégias planejadas e formuladas, é possível estreitar o fluxo de informações entre todos os envolvidos no processo."

O processo de comunicação, da forma como ocorre na instituição A, está de acordo com a recomendação de Mintzberg et al. (2010), visto que para os autores, a fase de implantação não pode ser pensada como processo independente, devendo ser realizada em conjunto com a formulação das estratégias. $\mathrm{Na}$ fase de formulação, as estratégias são elaboradas por meio de planos de ação que são desdobrados para os níveis tático e operacional. Conforme destaca o gestor da instituição E "as estratégias planejadas são passadas para as unidades de negócio que formulam estratégias de acordo com os objetivos que cada uma deseja”.

\subsection{PRINCIPAIS MOTIVAÇÕES PARA ADOÇÃO DO PROCESSO ESTRATÉGICO}

Nas cinco instituições consideradas, as respostas dos gestores convergiram em relação à motivação para a adoção do processo estratégico, a necessidade de sobrevivência diante da alta competitividade e o desejo de crescimento motivaram às instituições a formalizar a gestão estratégica. Como ressalta o gestor da instituição D "a necessidade de sobrevivência nos levou a praticar a gestão estratégica. Conforme a instituição vai crescendo, é necessário que se tomem ações que sustentem esse crescimento. "As respostas dos gestores de todas as instituições confirmam a visão de Machado (2008) que atribui o aumento da preocupação com a formalização da estratégia ao aumento da competitividade que se intensificou na década de 1990 com o crescimento do número de IES privadas no Brasil.

\subsection{PRINCIPAIS BARREIRAS EM CADA FASE DO PROCESSO}

No quadro 4 serão apresentadas resumidamente as barreiras encontradas pelos gestores para que o processo de gestão estratégica aconteça de forma eficaz. 
Quadro 4 Principais barreiras no processo de gestão estratégica

\begin{tabular}{|c|c|c|c|}
\hline Planejamento & Formulação & $\begin{array}{l}\text { Implantação/ } \\
\text { implementação }\end{array}$ & Controle \\
\hline $\begin{array}{l}\text { No planejamento, as } \\
\text { barreiras mais citadas } \\
\text { são referentes ao } \\
\text { excesso de } \\
\text { operacionalização e a } \\
\text { falta de } \\
\text { comprometimento dos } \\
\text { envolvidos, além de } \\
\text { mudanças no ambiente } \\
\text { externo, como enfatiza } \\
\text { o gestor da instituição } \\
\text { C “ mudanças na } \\
\text { legislação são } \\
\text { barreiras imprevisíveis } \\
\text { e podem modificar } \\
\text { todo o planejamento, a } \\
\text { última mudança, por } \\
\text { exemplo, em relação } \\
\text { ao FIES, pegou todo } \\
\text { mundo de surpresa e } \\
\text { por isso precisamos } \\
\text { reformular } \\
\text { rapidamente o nosso } \\
\text { planejamento." }\end{array}$ & $\begin{array}{l}\text { Nessa fase, os gestores } \\
\text { destacaram o fluxo de } \\
\text { informação que, é } \\
\text { dificultada pela falta de } \\
\text { comprometimento de } \\
\text { alguns dos envolvidos no } \\
\text { processo, ocasionando } \\
\text { atrasos na formulação. O } \\
\text { gestor da instituição A, } \\
\text { ainda destaca que "o atraso } \\
\text { na divulgação de dados } \\
\text { estatísticos faz com que se } \\
\text { planeje algo com base } \\
\text { numa realidade distorcida". } \\
\text { Outra barreira ressaltada } \\
\text { pelo gestor da instituição C } \\
\text { foi "a ausência de } \\
\text { informações completas e } \\
\text { alteraçôes políticas que } \\
\text { podem gerar a necessidade } \\
\text { de uma mudança na } \\
\text { estratégia em termos gerais, } \\
\text { inclusive a formulação de } \\
\text { novas estratégias. }\end{array}$ & $\begin{array}{l}\text { Nesta fase, a cultura } \\
\text { de resistência à } \\
\text { mudança é vista } \\
\text { como principal } \\
\text { barreira pelos } \\
\text { gestores, de acordo } \\
\text { com o gestor da } \\
\text { instituição E "a a } \\
\text { resistência de } \\
\text { determinadas áreas } \\
\text { por conta da } \\
\text { comodidade podem } \\
\text { dificultar a } \\
\text { implementação das } \\
\text { estratégias." O } \\
\text { gestor da instituição } \\
\text { B, complementa, ao } \\
\text { afirmar que "as } \\
\text { pessoas são as } \\
\text { maiores barreiras, a } \\
\text { falta de motivação e } \\
\text { compromisso de } \\
\text { alguns envolvidos } \\
\text { pode prejudicar todo } \\
\text { o processo." }\end{array}$ & $\begin{array}{l}\text { Em relação as } \\
\text { barreiras, mais uma } \\
\text { vez a questão da } \\
\text { cultura se destacou, } \\
\text { com exceção da } \\
\text { instituição A e E, } \\
\text { onde nenhuma } \\
\text { barreira foi } \\
\text { ressaltada, as demais } \\
\text { instituições destacam } \\
\text { a falta de motivação } \\
\text { dos envolvidos que } \\
\text { não veem o processo } \\
\text { como prioridade, } \\
\text { como ressaltado pelo } \\
\text { gestor E “a criação } \\
\text { dos indicadores nem } \\
\text { sempre é uma tarefa } \\
\text { fácil, e muitas vezes, } \\
\text { a área de TI coloca } \\
\text { outras tarefas como } \\
\text { prioridades." }\end{array}$ \\
\hline
\end{tabular}

Fonte: Dados da pesquisa (2015)

Como é possível observar no quadro 4, a falta de comprometimento e resistência de alguns dos envolvidos são destacados pelos gestores como barreiras em todas as fases do processo, corroborando com Barbosa e Drummond (2008) quando afirmam que ausência do envolvimento dos trabalhadores no processo de gestão é um dos principais empecilhos para a implantação eficaz da estratégia. As barreiras destacadas pelos gestores também estão de acordo com Andrade e Frazão (2011) que consideram que a organização é influenciada por fatores intrínsecos e extrínsecos e o planejamento favorece a correta utilização dos recursos perante as mutações.

\subsection{PRINCIPAIS FATORES FACILITADORES DE CADA FASE}

Em geral as instituições utilizam o Plano de Desenvolvimento Institucional como direcionador do planejamento, já que neste estão destacados a missão, visão e valores da instituição, além das metas definidas para um horizonte de tempo de 10 anos, estas metas são 
redimensionadas para um período anual e acompanhadas mensalmente, exceto na instituição A, onde o horizonte de tempo do planejamento coincide com o do PDI que é de dez anos.

Outro fator que facilita o processo nas organizações é a comunicação entre as fases, que para Silva (2003) é um fator determinante do sucesso ou do fracasso dos objetivos organizacionais. A comunicação para acompanhamento das estratégias é realizada, principalmente, em reuniões especificas em que são apresentados os planos de ações atualizados nos softwares de acompanhamento por meio de gráficos e/ou mapas, e anualmente é realizado um fechamento em que se verifica os status de todas as ações, comparando o que se planejou e o que se implementou efetivamente. Esses softwares e ferramentas como análise SWOT são alguns dos fatores que facilitam o processo de gestão estratégica, como é possível observar no quadro 5.

Quadro 5 Principais facilitadores no processo de gestão estratégica

\begin{tabular}{|c|c|c|c|}
\hline Planejamento & Formulação & $\begin{array}{l}\text { Implantação/ } \\
\text { implementação }\end{array}$ & Controle \\
\hline $\begin{array}{l}\text { Com relação aos } \\
\text { principais } \\
\text { facilitadores, os } \\
\text { entrevistados } \\
\text { apontaram a } \\
\text { tecnologia, como } \\
\text { ressaltado pelo } \\
\text { gestor da } \\
\text { instituição E “Os } \\
\text { insumos, que são } \\
\text { os dados coletados } \\
\text { e processados, são } \\
\text { essenciais para o } \\
\text { planejamento } \\
\text { estratégico e a } \\
\text { tecnologia é uma } \\
\text { importante aliada, } \\
\text { agilizando o } \\
\text { processo de } \\
\text { análise de grande } \\
\text { quantidade de } \\
\text { dados” }\end{array}$ & $\begin{array}{l}\text { A análise SWOT foi a } \\
\text { ferramenta citada por } \\
\text { todos os gestores no } \\
\text { auxílio desta fase que, } \\
\text { a partir das } \\
\text { informações } \\
\text { disponíveis, identifica } \\
\text { as oportunidades e } \\
\text { ameaças (ambiente } \\
\text { externo) assim como, } \\
\text { as forças e fraquezas } \\
\text { (ambiente interno) da } \\
\text { organização, } \\
\text { corroborando com } \\
\text { Mintzberg et al. } \\
\text { (2006) que destaca } \\
\text { que a visão global da } \\
\text { organização, facilitada } \\
\text { pela análise SWOT, } \\
\text { facilita a correta } \\
\text { formulação das } \\
\text { estratégias }\end{array}$ & $\begin{array}{l}\text { Já como facilitadores, os } \\
\text { mais citados foram } \\
\text { alguns softwares que } \\
\text { auxiliam no fluxo de } \\
\text { informações internas, } \\
\text { em que as estratégias } \\
\text { formuladas ficam } \\
\text { visíveis para que todos } \\
\text { os níveis } \\
\text { organizacionais tenham } \\
\text { acesso. O gestor da } \\
\text { instituição C, ainda } \\
\text { reconhece como } \\
\text { facilitadores, além dos } \\
\text { sistemas de informação } \\
\text { "A estrutura, que inclui } \\
\text { os recursos necessários } \\
\text { para a implementação } \\
\text { de tudo que foi } \\
\text { formulado. }\end{array}$ & $\begin{array}{l}\text { Como fatores que facilitam } \\
\text { essa fase, a maioria das } \\
\text { instituições destacaram } \\
\text { softwares, como enfatiza o } \\
\text { gestor da instituição B “O } \\
\text { que mais facilita para se } \\
\text { controlar as estratégias é a } \\
\text { utilização de um software } \\
\text { em que todas as ações são } \\
\text { elencadas e classificadas } \\
\text { como pendentes e } \\
\text { concluídas. O gestor da } \\
\text { instituição C, complementa } \\
\text { "Além dos softwares, o } \\
\text { próprio planejamento formal } \\
\text { é um fator essencial para } \\
\text { essa fase. " Corroborando } \\
\text { com Mintzberg et al. (2006) } \\
\text { que ressalta a } \\
\text { interdependência entre essas } \\
\text { duas fases. }\end{array}$ \\
\hline
\end{tabular}

Fonte: Dados da pesquisa (2015)

\section{CONSIDERAÇÕES FINAIS}

O objetivo geral desse estudo que foi identificar como ocorre o processo de gestão estratégica nas IES privadas cearenses foi subdividido em quatro objetivos específicos (1) 
identificar os principais atores de cada fase; (2) identificar as principais motivações; (3) identificar as principais barreiras na implementação das fases e; (4) identificar os fatores facilitadores de cada fase. Para responder aos objetivos foram realizadas entrevistas semiestruturadas com questões abertas com os gestores das IES privadas cearenses com o conceito institucional, de acordo com o MEC, igual ou maior que três. Os diretores acadêmicos e gerais foram os sujeitos da pesquisa e os resultados serão apresentados a seguir.

Em relação aos principais atores em cada fase, os gestores relatam que a alta administração, formada pelos diretores acadêmicos e gerais são os responsáveis direto pelo planejamento; os diretores e coordenadores de cursos são encarregados pela formulação; os coordenadores e suas respectivas equipes também direcionam a implementação e o controle, tendo nesta última fase, o envolvimento também dos diretores.

Quanto às principais motivações, verificou-se que a adoção da gestão estratégica nas IES tem como principal motivador o aumento da concorrência que, se intensificou a partir dos anos de 1990 através de políticas de financiamento estudantil. As barreiras encontradas pelas IES também convergiram e as mais citadas são referentes a cultura de resistência à mudança e informações atrasadas e incompletas que dificultam o processo como um todo desde o planejamento e formulação que se baseiam em tais informações, até a implementação que requer comprometimento de todos e o controle que necessita de informações atualizadas. E em relação aos fatores facilitadores de cada fase, foi observado semelhanças em todas as instituições. Os fatores facilitadores são formados, basicamente, por softwares que auxiliam no processo através do fluxo de informações em tempo real e controle das estratégias já implementadas. Além de ferramentas como análise SWOT e Balance Score Card.

Desse modo, é possível verificar que o processo de gestão estratégica nas IES ocorre de forma holística devido a própria dinâmica do processo, os atores do processo estão interligados, a cultura é uma das principais barreiras e a tecnologia um dos fatores que mais facilitam o processo.

Como contribuição gerencial, o estudo mostrou uma maior preocupação das IES em formalizar sua gestão estratégica e sugere-se que esta preocupação tenha relação com a maior profissionalização da gestão (4 dos 5 entrevistados são, pelo menos, mestre em administração de empresas). Além da visão da gestão estratégica como diferencial competitivo.

Como contribuição teórica, o estudo pode ser replicado em outras IES, como por exemplo os centros universitários e/ou universidades e realizada a comparação do processo de gestão entre as diferentes denominações de IES. Uma das limitações desse trabalho é o 
pequeno número de entrevistados em virtude do tempo e disponibilidade dos respondentes, além se considerar somente as IES da cidade de Fortaleza. Portanto, recomenda-se o desenvolvimento de estudos que abranjam um maior número de entrevistados permitindo assim uma visão mais aprofundada do processo de gestão estratégica.

\section{REFERÊNCIAS}

ALMINO, Tiago Henrique; NAKAYAMA, Marina Keiko; RAMOS, Alexandre Moraes; OLIVEIRA, Paulo Cristiano. A contribuição do PDI nas atividades de planejamento e gestão nas instituições de ensino superior. Revista Gestão Universitária na América Latina - GUAL, Florianópolis, v. 5, n. 3, p. 81- 107, 2012.

ANDRADE, Iracilma R. Silva; FRAZÃO, Maria de Fátima Araújo. Estratégia em ação. Revista de Gestão, Finanças e Contabilidade, UNEB, Salvador, v. 1, n. 1, p. 18-34, 2011.

ARAÚJO E SILVA, Flávia de; GONÇALVES, Carlos Alberto. O processo de formulação e implementação de planejamento estratégico em instituições do setor público. Revista de Administração da UFSM, v. 4, n. 3, p. 458-476, 2011.

BARBOSA, L. L. S.; DRUMMOND, A. O Processo de Implantação da Estratégia em uma Empresa do Setor Têxtil. In: ENCONTRO NACIONAL DOS PROGRAMAS DE PÓS-GRADUAÇÃO EM ADMINISTRAÇÃO, XXXII., 2008, Rio de Janeiro, Anais... Rio de Janeiro: EnANPAD, 2008.

BEPPLER, Mônica Külkamp; PEREIRA, Maurício Fernandes; COSTA, Alexandre Marino. Discussão conceitual sobre o processo de estratégia nas organizações: formulação e formação estratégica.Revista Ibero-Americana de Estratégia, v. 10, n. 1, p. 128-146, 2011.

BRASIL. Lei no 10.861, de 14 de abril de 2004. Institui o Sistema Nacional de Avaliação da Educação Superior - SINAES e dá outras providências. Diário Oficial da União, Poder Executivo, Brasília, DF, no 72, 15 abr. 2004. Seção 1, p. 03.

COELHO JUNIOR, Francisco Antônio. Gestão estratégica: um estudo de caso de percepção de mudança de cultura organizacional. Psico-USF, v. 8, n. 1, p. 81-89, 2003.

COLLIS, Jill; HUSSEY, Roger. Pesquisa em administração: Um guia prático para alunos de graduação e pós-graduação. 2. ed. Porto Alegre: Bookman, 2005.

E-MEC. Instituições de ensino superior e cursos cadastrados. Disponível em: https://emec.mec.gov.br/emec/nova . Acesso em 17 de maio de 2015.

GRAY, David E. Pesquisa no mundo real. 2. Ed. Porto Alegre: Penso, 2012.

HERNANDES, Gabrielle Junqueira; LOMBARDI, Marta Fabiano Sambiase. Um Estudo sobre o Processo de Gestão Estratégica em Instituições de Ensino Superior. RS. In: ENCONTRO DE ESTUdOS EM ESTRATÉGIA, V., 2011, Porto Alegre, Anais... Porto Alegre: ANPAD, 2011. 
INEP. Avaliação Institucional. Disponível em:http://portal.inep.gov.br/superioravaliacao institucional. Acesso em 19 de maio de 2015.

INEP. Sinopses Estatísticas da Educação Superior - Graduação,2013. Disponível em: http://portal.inep.gov.br/superior-censosuperior-sinopse . Acesso em: 19 de maio de 2013.

MACHADO, Luís Eduardo. Gestão estratégica para instituições de ensino superior privadas. FGV Editora, 2008.

MAINARDES, Emerson Wagner; MIRANDA, Cristina Schmitt; CORREIA, Carlos Henrique. A gestão estratégica de Instituições de Ensino Superior: Um estudo multicaso. Contextus-Revista Contemporânea de Economia e Gestão, v. 9, n. 1, p. p. 19-32, 2011.

MATOS, Osvair A.; VENÂNCIO, Daniella M.; DUTRA, Ademar. Gestão estratégica em instituições de ensino superior: mapeamento das publicações científicas no período de 1997 a 2012. Revista GUAL, Florianópolis, v. 7, n. 1, p. 106-127, jan. 2014.

MAY, Tim. Pesquisa social: questões, métodos e processos. 3. Ed., Porto Alegre: Artmed, 2004.

MINTZBERG, Henry; LAMPEL, Joseph; QUIN, James Brian; GHOSHAL, Sumantra. O Processo da Estratégia. 4. ed. Bookman, 2006.

MINTZBERG, H.; AHLSTRAND, B.; LAMPEL, J. Safári de Estratégia. 2. ed. Porto Alegre: Bookman, 2010.

NICOLAU, Isabel. O conceito de estratégia. Lisboa: INDEG/ISCTE, 2001.

OLIVEIRA JUNIOR, Zacarias Gonçalves de; CASTRO, Dagmar Silva Pinto de. Gestão estratégica da tecnologia de informação em uma instituição de ensino como diferencial competitivo. In ENCONTRO DA ANPAD, 30., 2006, Salvador, Anais... Salvador: EnANPAD, 2006. p. 1-16.

OLIVEIRA, Greycielle Alves et al. Planejamento Estratégico em Micro e Pequenas Empresas-Estudo Multicaso no Setor de Alimentação em Goiânia (GO). Estudos, v. 42, n. 1, p. 125-136, 2015.

ROESCH, Sylvia Maria Azevedo. Projetos de estágio e de pesquisa em administração: guia para estágios, trabalhos de conclusão, dissertações e estudos de caso. 3. ed., São Paulo: Atlas, 2006.

SARFATI, Gilberto; SHWARTZBAUM, Alan David. Sinergias nas fusões e aquisições do setor de educação superior no Brasil. Revista Pensamento Contemporâneo em Administração. v. 7, n. 4, Rio de Janeiro, 2013 
SILVA, Andressa Hennig; FOSSÁ, Maria Ivete Trevisan. Análise de conteúdo: exemplo de aplicação da técnica para análise de dados qualitativos. Qualit@s Revista Eletrônica, v. 1, n. $1,2015$.

SILVA, Leandro Costa da. O balanced scorecard e o processo estratégico. Caderno de pesquisas em administração, v. 10, n. 4, p. 61-73, 2003.

SILVA, Maria Caroline Carneiro et al. Contribuição do Plano de Desenvolvimento Institucional como ferramenta de planejamento estratégico na gestão de uma instituição privada de ensino superior do Recife. Revista Gestão Universitária na América LatinaGUAL, v. 7, n. 3, p. 77-92, 2014.

WEBER, Marcos; KLEIN, Amarolinda Zanela. Gestão Estratégica em Empresas de Tecnologia da Informação: Um Estudo de Caso. Revista Ibero-Americana de Estratégia, v. 12, n. 3, p. 37-65, 2013. 